\title{
PANORAMA SOBRE LA PRODUCCIÓN Y EL CONSUMO DE LECHE Y LÁCTEOS EN MÉXICO
}

\section{OUTLOOK OF MILK AND DAIRY PRODUCTION AND CONSUMPTION IN MEXICO}

\author{
Juan Miguel Rodríguez Salomón*, Aída Beatriz Armenta Ramírez**
}

\begin{abstract}
*Licenciado en Economía. Universidad Juárez Autónoma de Tabasco. División Académica de Ciencias Económico Administrativas. ORCID: https://orcid.org/0000-0002-4696-8653

**Doctora en Economía. Centro de Estudios Socioeconómicos (CISE) de la Universidad Autónoma de Coahuila (UAdeC). Email: handel91@gmail.com. ORCID: https://orcid.org/0000-0002-0248-4665
\end{abstract}

Dirección para recibir correspondencia: juanrodriguezsalomon@gmail.com 
PANORAMA SOBRE LA PRODUCCIÓN Y EL CONSUMO DE LECHE Y LÁCTEOS EN MÉXICO

\title{
RESUMEN
}

OBJETIVO: Ilustrar el panorama general sobre el consumo de leche y lácteos en México durante el periodo 2015-2017.

MATERIAL Y MÉTODO: Se trata de una investigación documental analítica retrospectiva, basada en los datos reportados sobre la producción, comercialización y gasto familiar sobre los productos de la industria lechera en México.

RESULTADOS: La industria lechera mexicana acarrea un déficit en su balanza de pagos y su consumo provoca un gasto en los hogares entre el $7.91 \%$ y el $11.22 \%$.

CONCLUSIONES: De acuerdo a los patrones de consumo en México, la leche y los lácteos son bienes normales con una relación inversa entre gasto y demanda. El mercado lechero en México es insuficiente para cubrir a la demanda interna.

PALABRAS CLAVE: Leche. Lácteos. Producción. Consumo. Gasto.

\begin{abstract}
OBJECTIVE: To illustrate the general outlook of milk and dairy products in Mexico during 20152017.

MATERIAL AND METHOD: This is a retrospective analytic documental research based on the reported date over production, trade and familiar expenditure on products of the Mexican milk industry.
\end{abstract}

RESULTS: The Mexican milk industry carries a shortfall of the balance of payment and its consumption leads to a household expenditure of $7.91 \%-11.22 \%$.

CONCLUSIONS: In accordance to the Mexican consumption patterns, milk and dairy are normal goods that hold a converse relation between its expenditure and demand. The milk industry in Mexico is insufficient to cover the domestic consumption.

KEY WORDS: Milk. Dairy. Production. Consumption. Expenditure. 


\section{PANORAMA SOBRE LA PRODUCCIÓN Y EL CONSUMO DE LECHE Y LÁCTEOS EN MÉXICO}

\section{INTRODUCCIÓN}

En una época donde existe la mayor oferta de alimentos, es la economía la que define el excedente global a través de la configuración de la estructura de precios. Al mismo tiempo, se construye en la sociedad una paradoja debido a que dentro de una sociedad dividida en estratos, el único sector que puede seleccionar el alimento preciso para su salud es el que se encuentra en el estrecho vértice de la pirámide social. En cambio, el sector social del decil más pobre se ve obligado a sobrevivir con una mala calidad alimentación de bajos contenidos nutricionales. La diferencia en el tipo de ingreso ocasiona que la alimentación esté principalmente determinada en función al ingreso, es por ello que el acceso a los productos de la canasta básica variará en cada sector social. Asimismo, existen otras variables que determinarán dichos patrones de consumo de alimentos, tales como: los cambios sociodemográficos, la incorporación de servicios alimentarios y la publicidad. La presente investigación únicamente estudiará la relación directa entre consumo e ingreso.

Martínez y Villezca (2006) redactan que en México a finales de los años 90's, el sector de menor ingreso destinaba el 56\% de su gasto a la alimentación; a diferencia, el sector con el ingreso más alto empleaba sólo el $20 \%$ de su gasto total en alimentos. Esto demuestra que cuando el poder adquisitivo es bajo, el ingreso se destina a cubrir apenas las necesidades básicas, siendo la alimentación la más importante. Por lo contrario, cuando el poder adquisitivo es mayor, habiendo cubierto la alimentación, es posible destinarlo en educación, transporte y entretenimiento. Dentro de la alimentación, se presentaron variaciones de productos de acuerdo al tipo de ingreso. En promedio (en pesos del año 1998), el consumo de carne representaba el mayor gasto, 308 pesos mensuales; el sector más pobre destinaba 141 pesos para adquirirla y 505 pesos el sector más rico. El consumo significó la mayor aportación de proteínas sólo para los hogares más ricos. En segunda posición se encontraban los cereales, con un gasto medio de 195 pesos mensuales. Las familias con menores ingresos gastaban 118 pesos, siendo el $47 \%$ de lo que gastaban los más ricos (249 pesos). A pesar de que los cereales representaran el segundo mayor gasto de los más pobres, su consumo aportó la mayor cantidad de calorías (3,604 Cal) y proteínas (83 gr) a su dieta. Quienes se establecieron en el segundo mayor gasto en las familias mejor remuneradas fueron la leche y los lácteos, destinando 303 pesos. A diferencia, en las familias más pobres estos productos generaban el cuarto mayor gasto. Es por ello, que a nivel nacional los lácteos se ubicaron como el tercer mayor gasto. El consumo de leche y lácteos es parte del gasto en la alimentación de los mexicanos. 
PANORAMA SOBRE LA PRODUCCIÓN Y EL CONSUMO DE LECHE Y LÁCTEOS EN MÉXICO

Torres (1999) señala que la cantidad consumida de leche y lácteos estaba determinada por su nivel ingresos, ya que sólo en los sectores socioeconómicos alto y medio se encontraban el mayor consumo de leche y lácteos. Las familias más pobres gastaban $7 \%$ de sus ingresos en estos productos; mientras que las familias ricas utilizaban $12 \%$ del total, con un consumo predominado por yogurt, queso, leche pasteurizada, evaporada y condensada. Siempre existirán variaciones en el gasto en función a su ingreso.

De acuerdo con Hernández y Hernández (2016), en el año 2016 los consumidores con mayor poder adquisitivo se han convertido más conscientes de lo que consumen; al ser los únicos con la capacidad económica suficiente para determinar lo que desean consumir, han ido modificado sus patrones de consumo al procurar calidad y beneficios para la salud en los productos relacionados con la leche. Por ello, la industria de la leche se ha visto en la necesidad de diseñar estrategias de innovación para ser más competitivos en el mercado; mientras tanto, la creciente tendencia al consumo de productos sustitutos de la leche, tales como: la leche de almendras, soya, arroz y coco, ha conseguido modificar ciertos patrones de consumo dentro del gasto de las familias más ricas.

El consumo de leche es considerado, por tradición, un producto necesario dentro de la alimentación humana. Dicho consumo ha ido expandiéndose por el mundo a través de los años. Los ancestros de las vacas, los llamados aurochs, fueron domesticados en Europa, Asia y el norte de África. A partir de esta domesticación, ocurrió su evolución; y, con ello, el aprovechamiento de los recursos que se obtenían. La primera ordeña fue realizada en Europa, aunque la habilidad para poder digerir la leche correctamente ocurrió hasta cien o doscientos años después. Las actividades de ordeña comenzaron a esparcirse por el resto de Europa, Asia y África y, así, la leche comenzó a considerarse un regalo de la naturaleza a los humanos. Diversos grupos étnicos adjudicaron aspectos religiosos a las vacas, considerándolas animales sagrados debido a sus capacidades de creación de un alimento orgánico que podía nutrir a la sociedad: la leche. Las creencias de la religión hindú explican que la vaca fue el primer animal creado por los dioses, mismo que fue admirado y respetado por la sociedad. En Grecia, una leyenda narra que Zeus, rey de los dioses, obtuvo su fuerza para vencer a su padre gracias a la miel y la leche con la que se alimentó. Asimismo, los egipcios confiaban que la vaca era un dios y la nombraron como Hathor, cuya labor era cuidar la fertilidad de la tierra y que los niveles de agua del río Nilo fuesen altos. Incluso en la Biblia se relatan 55 referencias acerca de la leche, dándole un sentido metafórico de privilegios y bendiciones espirituales, (Schmid, 2009). 
PANORAMA SOBRE LA PRODUCCIÓN Y EL CONSUMO DE LECHE Y LÁCTEOS EN MÉXICO

La cría de ganado vacuno llegó a México hasta después de la invasión española, tal como lo narra Schmid (2009). Siendo en el año 1525 donde llega el primer ganado a la ciudad de Villa Rica de la Vera Cruz (actual ciudad de Veracruz) que, después de reproducirse, logró expandirse por todo Nuevo México. Durante los primeros 400 años, el ganado fue utilizado únicamente por su carne, sin embargo, el interés por la ordeña fue creciendo paulatinamente debido al incremento de la demanda de leche. Para el año 1972, la compañía mexicana productora de leche Alpura ya había logrado convertirse en la primera en expandirse por todo el país, misma quien activó la industria de leche en México. Como consecuencia a todo lo acontecido, la leche se convirtió en parte de la dieta mexicana.

La leche, de acuerdo a Cerón y Calvo (2010), es aquel líquido blancuzco complejo que segregan las glándulas mamarias de los mamíferos femeninos después de dar a luz a sus crías, el cual tiene un sabor dulce y cuenta con un PH casi neutral. La leche es un producto utilizado únicamente como alimento para las crías durante su periodo crítico de existencia después del nacimiento. También es considerada como el mejor suplemento para los mamíferos debido a las propiedades nutricionales que posee; principalmente moléculas de lactosa, lípidos y proteínas. De acuerdo a la Norma Oficial Mexicana (NOM), la fórmula de la leche debe consistir de caseína, grasas, suero y agua.

De acuerdo con Aportela (2010), los lácteos representan a aquel grupo alimenticio conformado a base de leche, tal como: el yogurt y el queso. Oficialmente, la crema y la mantequilla no son consideradas lácteos, a pesar de su origen; se ubican en el grupo de las grasas ya que no cuentan con cantidades suficientes de nutrientes. En contraste, otros productos, como los helados, sí se consideran como lácteos a pesar de su contenido mínimo de leche. La cantidad mínima de leche descrita dentro un producto lácteo debe ser de $22 \mathrm{~g} / \mathrm{L}$, del cual $70 \%$ puede ser caseína y puede poseer grasas vegetales.

De acuerdo con How Milk Gets from the Cow to the Store (2011), para que la leche sea comercializada en el mercado existe un largo proceso divido en 8 principales pasos: Crianza, Cosecha, Almacenamiento, Transportación, Pruebas de Laboratorio, Tratamiento, Empaquetamiento y Ventas. La crianza consiste en la concentración de las vacas y su alimentación con cereales, heno, ensilaje, comida procesada o pasto; a veces son utilizadas hormonas de crecimiento y antibióticos para incrementar la producción de leche. La cosecha se realiza durante el periodo de lactancia de los terneros, al crear pulsaciones alrededor de las

RODRÍGUEZ-SALOMÓN J. M., ARMENTA-RAMÍREZ A. B. 
PANORAMA SOBRE LA PRODUCCIÓN Y EL CONSUMO DE LECHE Y LÁCTEOS EN MÉXICO

tetillas de la ubre de la vaca para que se libere leche, proceso conocido como ordeña, realizado a mano o con máquinas ordeñadoras especializadas. En el almacenamiento se refrigera la leche dentro de recipientes especiales a unos $36^{\circ} \mathrm{F}$ durante no más de 48 horas mientras se agita para evitar la separación de la grasa animal. En la transportación se utilizan camiones especiales para trasladar la leche en tanques de acero inoxidable, permitiendo que permanezcan las cualidades de temperatura, apariencia y olor. En las pruebas de laboratorio se examina el contenido de grasas, proteínas, células y bacterias. En el tratamiento se lleva a cabo la pasteurización, homogenización y separación. Al pasteurizar se calienta la leche para eliminar bacterias, aunque se pierden nutrientes natos de la misma. Al homogenizar se separa la grasa para que sea clasificada como leche entera, baja en grasa y descremada. De lo obtenido, cierta cantidad se destina para convertirse en lácteos, mientras otra pasa a ser empaquetada y, finalmente, se encuentra lista para ser comercializada en el mercado.

El mercado de la leche en el mundo tiene una trayectoria centenaria, misma que va de la mano de la cultura y de la historia de cada región. El consumo de leche inició en México 493 años atrás y su poder en el mercado se ha ido incrementando generación tras generación, a base de estereotipos, creencias e influencias de la industria lechera mundial. El incremento de la demanda de la leche, así como de cualquier producto de la canasta básica, provoca incrementos en el gasto familiar y exige una mayor oferta de productos lecheros en el mercado.

La economía, como ciencia social, tiene la responsabilidad de no sólo estudiar la administración de los recursos escasos en el mercado para satisfacer las necesidades de la sociedad, sino también comprender su impacto social a través de la interpretación de datos económicos, y así, generar alternativas que procuren el bienestar común.

Objetivo general: La presente investigación, tiene el objetivo de ilustrar el panorama general sobre el consumo de leche y lácteos en México durante el periodo 2015-2017, mediante el análisis de su producción, exportaciones, importaciones, alcance y consumo dentro de la sociedad mexicana.

\section{Objetivos específicos:}

- Comparar el volumen de producción y comercialización de la leche y lácteos.

- Determinar su consumo a nivel nacional.

- Analizar el gasto familiar que genera dicho consumo. 


\section{PANORAMA SOBRE LA PRODUCCIÓN Y EL CONSUMO DE LECHE Y LÁCTEOS EN MÉXICO}

- Evaluar el gasto generado por estrato socioeconómico.

A partir de los datos obtenidos se podrán generar conclusiones acerca de las actividades de la industria lechera en el mercado mexicano desde un punto de vista económico. La importancia de su estudio radica en el choque de ideologías ante el acojo o rechazo de la leche dentro de los patrones de consumo de alimentos en México.

\section{MATERIAL Y MÉTODO}

La presente es una investigación documental analítica retrospectiva basada en los datos reportados sobre la producción, exportación, importación, consumo y gasto familiar sobre los productos de la industria lechera en México. Para determinar el concepto de lácteos, fue preciso incluir todos los productos que coloquialmente se consideran como lácteos: leche líquida, en polvo, condensada y evaporada, así como queso, yogurt, crema y mantequilla.

Para los datos de producción, exportación e importación de leche y lácteos fueron analizadas las cifras presentadas en el Food Outlook (Panorama de la Comida) publicado por la Organización de las Naciones Unidas para la Alimentación y la Agricultura, conocida por sus siglas en inglés como FAO. En la tabla se presentan los niveles productivos y de comercio exterior con mayor poder en el mercado de lácteos a nivel mundial. La información fue seleccionada del periodo 2015 al 2017 y se obtuvo una media. Sólo fueron seleccionadas 12 áreas económicas que ocupaban las mayores intervenciones en el mercado internacional, incluyendo México, para que fuesen comparadas. Las cantidades están representadas en toneladas y se encuentran redondeadas para su facilitar su interpretación:

Tabla 1

Producción, exportación e importación de leche y lácteos en México

\begin{tabular}{cccc}
\hline Años & Producción & Exportación & Importación \\
\hline 2015 & 11,570 & 205 & 3,327 \\
2016 & 11,757 & 327 & 3,692 \\
2017 & 11,968 & 926 & 3,958 \\
\hline
\end{tabular}

Fuente: FAO Food Outlook (2017).

Los datos anteriormente seleccionados fueron analizados de acuerdo a los principios de la teoría macroeconómica acerca de la demanda global $\left(O_{g}\right)$ y la oferta global $\left(D_{g}\right)$, que al encontrarse dentro del punto de equilibrio, es posible su comparación. El equilibro será representado como la igualdad entre la suma de la producción $(Y)$ más las importaciones $(M)$ y RODRÍGUEZ-SALOMÓN J. M., ARMENTA-RAMÍREZ A. B. 
la suma del consumo $(C)$, la inversión $(I)$, el gasto público $(G)$ y las exportaciones $(X)$. La fórmula de este equilibrio es la siguiente:

$$
\begin{gathered}
O_{g}=D_{g} \\
Y+M=C+I+G+X
\end{gathered}
$$

De dicha fórmula fueron excluidas las inversiones $(I)$ y el gasto público $(G)$ debido a que ambas no representan una influencia directa dentro del consumo de leche y lácteos para esta investigación. Las inversiones que realizan los empresarios dentro de la industria pecuaria se destinan principalmente a la cría de ganado para consumo de su carne; las acciones del gasto público carecen de una relación con la industria lechera ya que no existen leyes que regulen el consumo de estos productos. Al despejar el consumo, habiendo especificado lo anterior, se obtuvo que la cantidad consumida sería interpretada por la siguiente ecuación:

$$
C=Y+M-X
$$

Para determinar el consumo per cápita en México se consideraron los datos sobre la población total mexicana publicados por el Instituto Nacional de Estadística y Geografía (INEGI) con base en los tres años del presente estudio. En el proceso, se consideró que de 0.1 toneladas, se obtienen 101.83 litros; asimismo, que una tasa de leche equivale a 250ml:

Tabla 2

Población total mexicana

\begin{tabular}{lc}
\hline Años & Población Total Mexicana \\
\hline 2015 & $125,890,949$ \\
2016 & $127,540,423$ \\
2017 & $129,163,276$ \\
\hline
\end{tabular}

Fuente: INEGI (2017).

Para conocer el alcance al consumo de leche y lácteos de las familias mexicanas se analizó la Encuesta Nacional de Ingreso - Gasto de los Hogares (ENIGH) proporcionada por el Instituto Nacional de Estadística y Geografía (INEGI). Los datos son los referentes al año 2016 y se encuentran clasificados por deciles de acuerdo a los múltiplos de salarios mínimos en México: 
PANORAMA SOBRE LA PRODUCCIÓN Y EL CONSUMO DE LECHE Y LÁCTEOS EN MÉXICO

Tabla 3

Gasto en leche y lácteos por decil de múltiplos de salarios mínimos en México

\begin{tabular}{cccc}
\hline Deciles & Múltiplos de Salario Mínimo $(\mathrm{x})$ & Leche y Lácteos $(\mathrm{y})$ & Porcentaje \\
\hline 1 & 0.00 a 1.00 & 245,814 & $0.88 \%$ \\
2 & 1.01 a 1.50 & 568,476 & $2.05 \%$ \\
3 & 1.51 a 2.00 & 871,369 & $3.14 \%$ \\
4 & 2.01 a 3.00 & $2,718,402$ & $9.81 \%$ \\
5 & 3.01 a 4.00 & $3,186,185$ & $11.50 \%$ \\
6 & 4.01 a 5.00 & $3,107,498$ & $11.22 \%$ \\
7 & 5.01 a 6.00 & $2,719,911$ & $9.82 \%$ \\
8 & 6.01 a 7.00 & $2,401,418$ & $8.67 \%$ \\
9 & 7.01 a 8.00 & $1,769,819$ & $6.39 \%$ \\
10 & 8.01 y más & $10,095,218$ & $36.46 \%$ \\
& Total & $27,684,110$ & $100 \%$ \\
\hline
\end{tabular}

Fuente: INEGI (2017).

Asimismo, se determinó el nivel de consumo de leche y lácteos en comparación con los demás alimentos localizados en el gasto de la dieta mexicana y para conocer la tendencia por hogares en México. Para aproximar la relación de dependencia entre estas dos variables se realizó una regresión lineal simple, sin embargo, fue necesario realizar una regresión exponencial para obtener un mejor ajuste de datos. En ambas regresiones los deciles divididos por múltiplos de salario mínimo representan a los datos de $\boldsymbol{x}$, y el consumo por toneladas de leche y lácteos representan a $\boldsymbol{y}$. El cálculo de la regresión fue determinado mediante las siguientes ecuaciones:

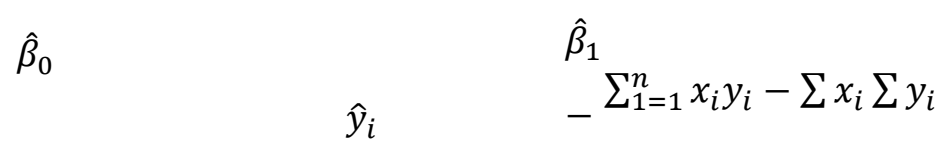

\section{RESULTADOS}

Los resultados que se presentan a continuación efectivamente ofrecen un panorama acerca de la industria lechera nacional. México se posicionó a nivel mundial en el noveno puesto con una producción promedio de 11,765 toneladas durante el periodo 2015-2017; este dato, a pesar de 


\section{PANORAMA SOBRE LA PRODUCCIÓN Y EL CONSUMO DE LECHE Y LÁCTEOS EN MÉXICO}

alentador, es insignificante en comparación con los países más productivos. México produce únicamente $7.44 \%$ de la producción en India, quien ocupa la segunda posición. La industria lechera es regida en su mayoría por la Unión Europea, India y Estados Unidos. El total de producción se ha ido incrementado año con año. Conforme al nivel de comercio exterior, las exportaciones mexicanas únicamente representan el $4.13 \%$ de la producción nacional, lo que indica que los productos mexicanos de leche y lácteos no tuvieron fuerza en el mercado mundial. Por lo contrario, el nivel de importaciones se elevó en gran medida. El total de importaciones fue 7.42 veces que su nivel de exportaciones, colocándolo como el tercer país que más importa leche y productos lácteos, sólo después de China y Rusia. El consumo nacional e internacional se presentó de la siguiente manera:

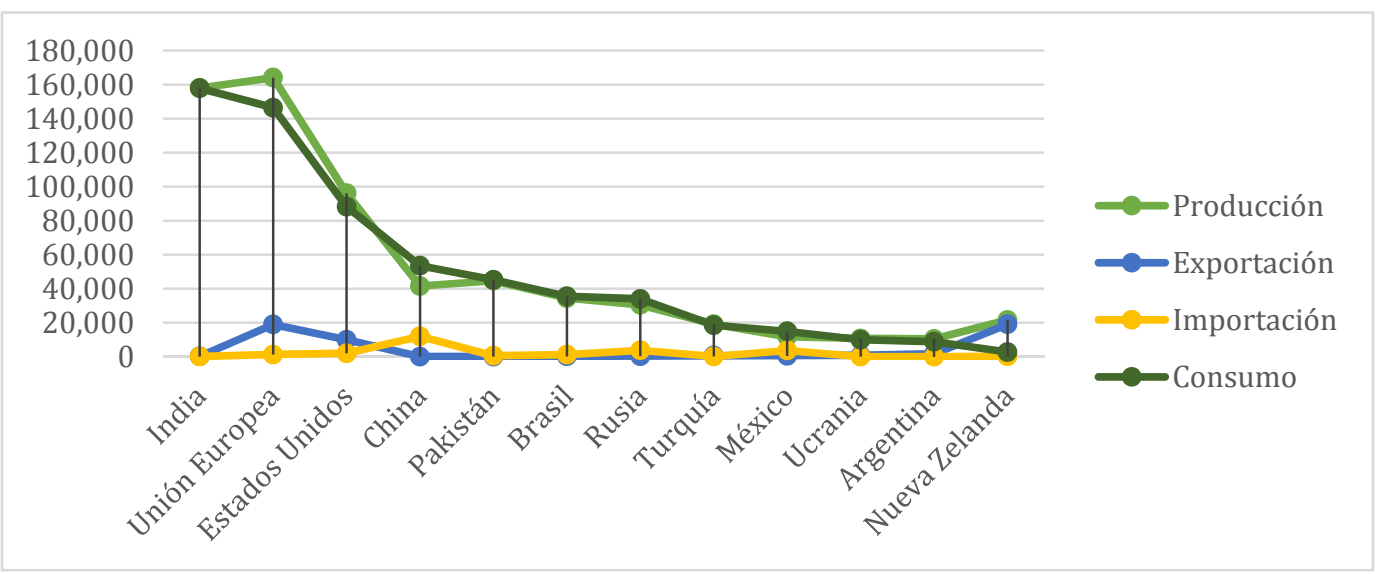

Figura 1. Industria de la leche y lácteos a nivel mundial.

Fuente: Elaboración propia.

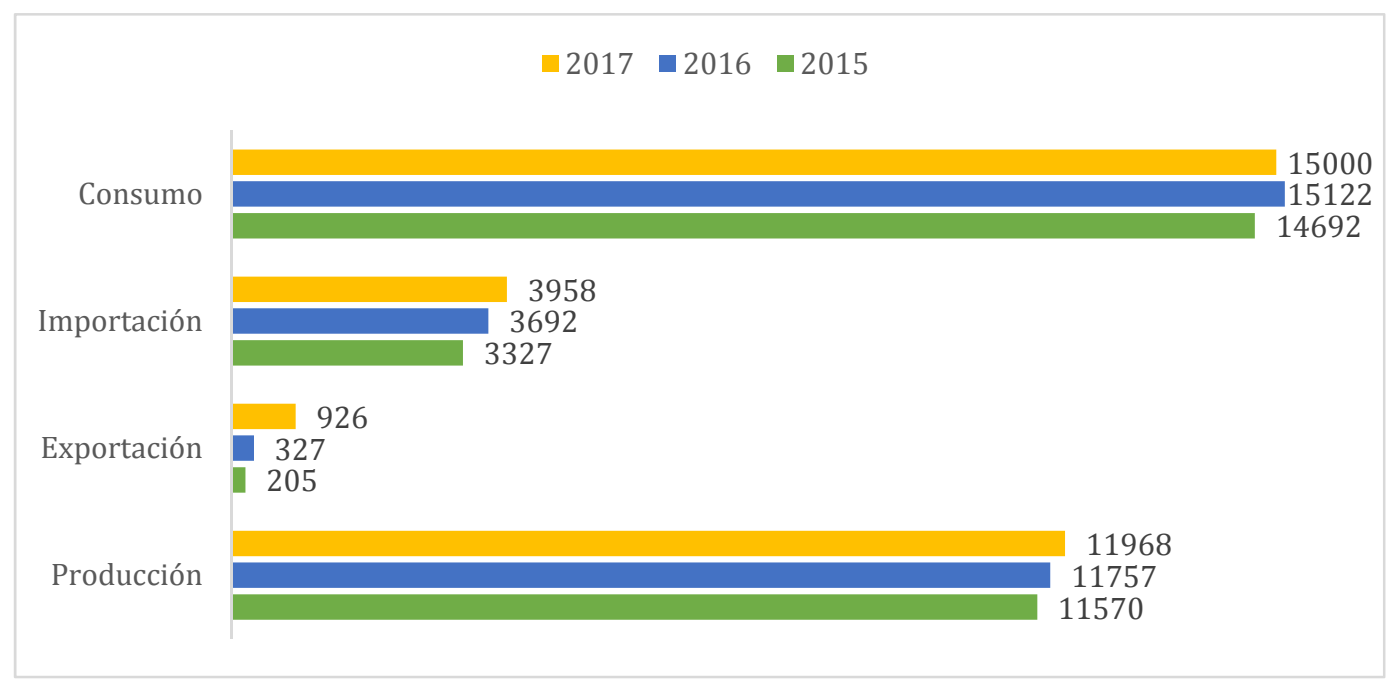

Figura 2. Industria de la leche y lácteos en México.

Fuente: Elaboración propia.

RODRÍGUEZ-SALOMÓN J. M., ARMENTA-RAMÍREZ A. B. 
PANORAMA SOBRE LA PRODUCCIÓN Y EL CONSUMO DE LECHE Y LÁCTEOS EN MÉXICO

El consumo de leche y lácteos en México superó a la producción nacional; en promedio, México consumió 14'938,000 toneladas durante el periodo 2017-2016, y per cápita fueron consumidos 0.33 litros diariamente.

Tabla 3

Consumo de leche y lácteos en México

\begin{tabular}{lcccc}
\hline Años & 2015 & 2016 & 2017 & Promedio \\
\hline Población total mexicana & $125,890,949$ & $127,540,423$ & $129,163,276$ & $127,531,549$ \\
Consumo total en toneladas & $14,692,000$ & $15,122,000$ & $15,000,000$ & $14,938,000$ \\
Consumo per cápita en toneladas & 0.12 & 0.12 & 0.12 & 0.12 \\
Consumo per cápita en litros & 118.84 & 120.74 & 118.26 & 119.28 \\
Consumo per cápita en tasas & 475.37 & 482.96 & 473.04 & 477.12 \\
Consumo diario per cápita en litros & 0.33 & 0.33 & 0.32 & 0.33 \\
Consumo diario per cápita en tasas & 1.30 & 1.32 & 1.30 & 1.31 \\
\hline
\end{tabular}

Fuente: Elaboración propia.

Dentro de la dieta mexicana, la leche y los lácteos se posicionaron como el cuarto producto al cual las familias mexicanas dedican mayor gasto, coincidiendo en todos los sectores socioeconómicos; se ubican sólo por debajo de los cereales, la carne y el grupo de verduras, legumbres, leguminosas y semillas. Quien realizó el menor gasto fue el decil 1 (0.00 a 1.00), ya que dedica \$10 095218 MXN, que representa únicamente el 0.88\% del consumo nacional de leche y lácteos. Mientras tanto, el decil 10 (8.01 y más) consiguió el mayor gasto ya que dedican $\$ 245,814$ MXN en estos productos, mismo que es el $36 \%$ del consumo nacional de leche y lácteos.

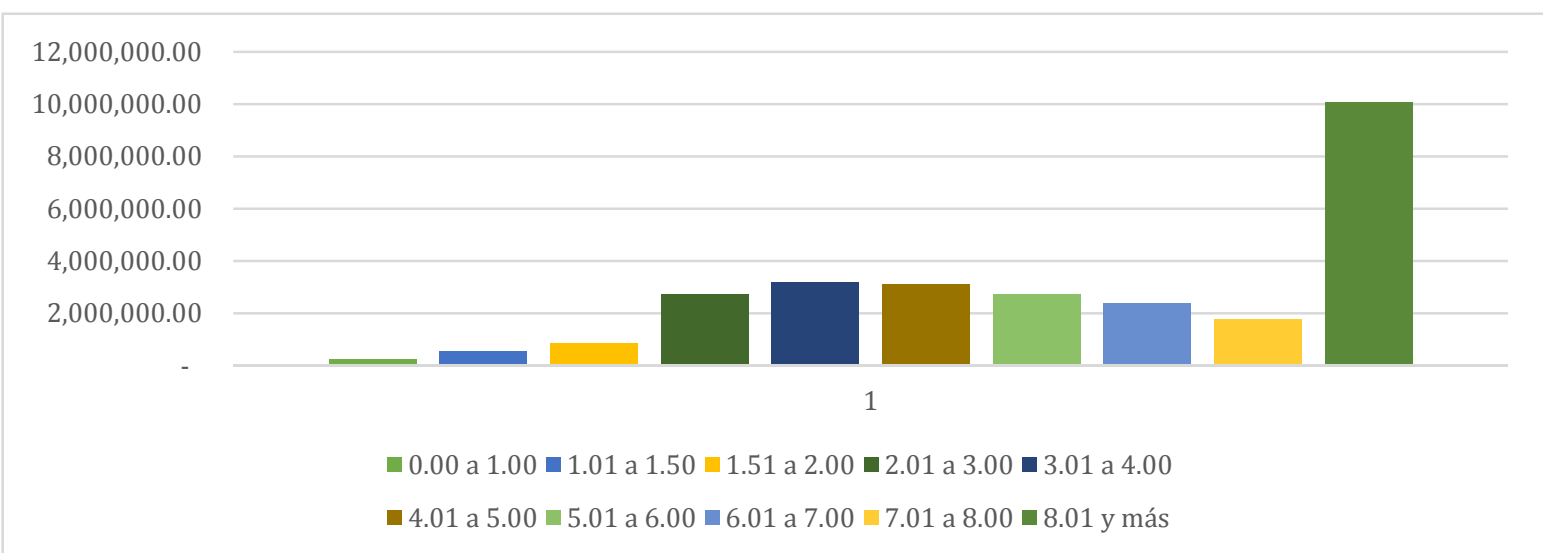

Figura 3. Gasto total en leche y lácteos en México por decil.

Fuente: Elaboración propia.

RODRÍGUEZ-SALOMÓN J. M., ARMENTA-RAMÍREZ A. B. 


\section{PANORAMA SOBRE LA PRODUCCIÓN Y EL CONSUMO DE LECHE Y LÁCTEOS EN MÉXICO}

Debido a la larga brecha de desigualdad que existe en México, resulta difícil comprender los patrones de consumo, sólo a partir del gasto total realizado por deciles; por ello, fue necesario comparar los porcentajes de gasto de leche y lácteos conforme al gasto total de alimentos por cada decil. El porcentaje de consumo de leche y lácteos en México tiene una tendencia a la alta, no obstante, el rango entre el menor y el mayor decil es similar; las familias con menores ingresos destinan $7.91 \%$ del gasto total en alimentos y las familias con mayores ingresos gastan $11.22 \%$. El noveno decil es el único que presenta una pequeña disminución en el gasto en comparación a su ingreso total.

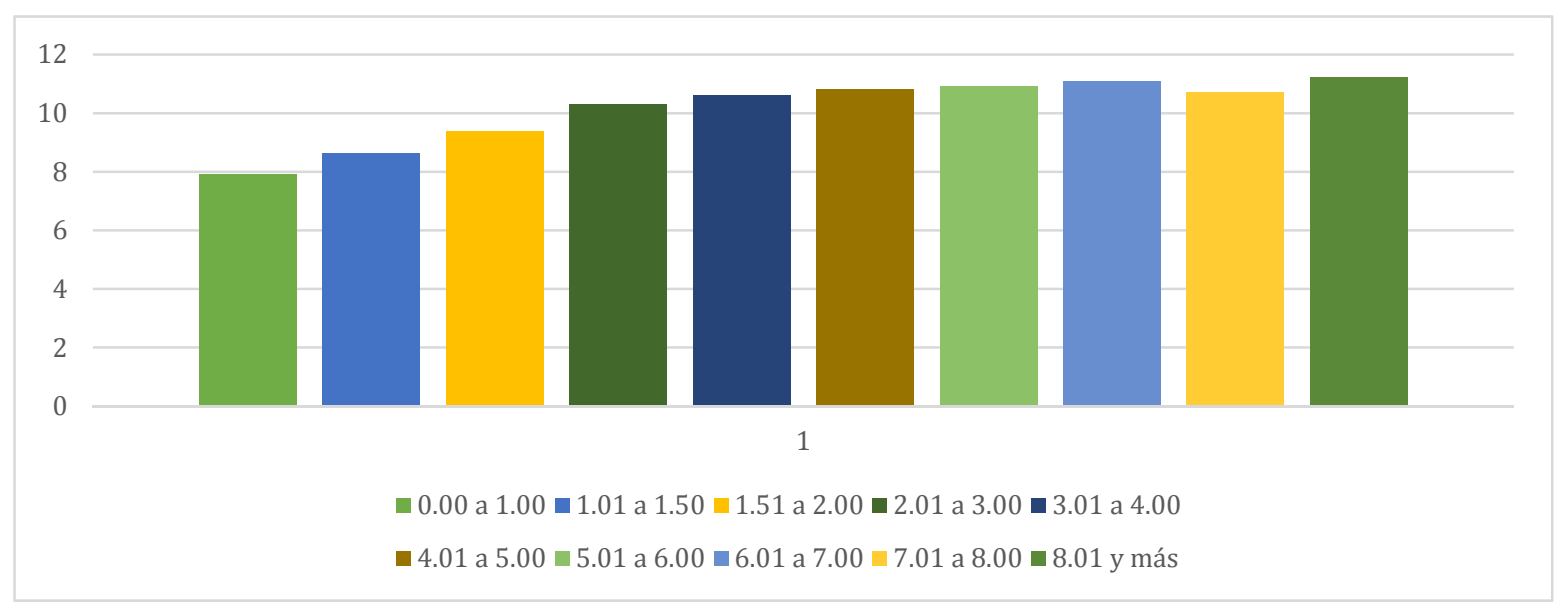

Figura 4. Porcentaje de gasto en leche y lácteos de acuerdo a gasto en alimentos por decil. Fuente: Elaboración propia.

En cuanto a los datos de las regresiones, se percibe que hay una tendencia creciente de acuerdo al gasto en leche y lácteos por decil, donde se observa una curva de gasto lineal. La regresión que proporciona un mayor ajuste a los datos es la exponencial, cuyos resultados fueron utilizados para la comprensión de estos datos. La regresión exponencial cuenta con un coeficiente de relación de 0.81 , lo que indica que efectivamente hay una relación entre estados variables. Además posee una bondad de ajuste del $62 \%\left(R^{\wedge} 2=0.62\right)$ y consigue explicar la tendencia al gasto de leche y lácteos por decil correctamente, ya que se encuentra mayor al $50 \%$. El estadístico $t$ se encuentra muy elevado y, por ello, cuenta con una probabilidad muy baja, casi de cero (0.000000002); la media que estima el modelo está lejos de la ideal y proveería una baja veracidad al utilizarla como prueba de hipótesis. 


\section{PANORAMA SOBRE LA PRODUCCIÓN Y EL CONSUMO DE LECHE Y LÁCTEOS EN MÉXICO}

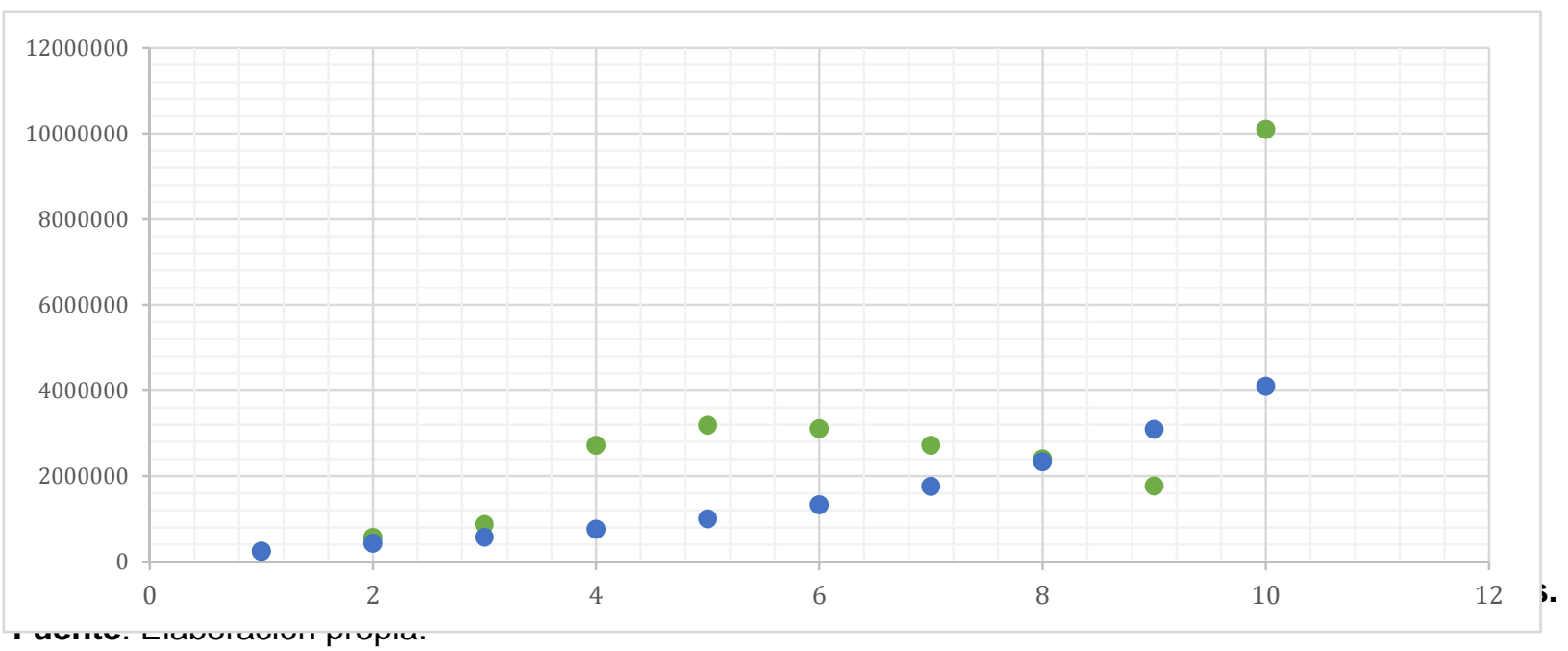

Tabla 5

Resultados de la regresión exponencial

\begin{tabular}{lc} 
Estadísticas de la regresión exponencial & \\
\hline Coeficiente de correlación múltiple & 0.8148 \\
Coeficiente de determinación $\mathrm{R}^{\wedge} 2$ & 0.6639 \\
$\mathrm{R}^{\wedge} 2$ ajustado & 0.6219 \\
Error típico & 0.6428 \\
Observaciones & 10 \\
\hline
\end{tabular}

Fuente: Elaboración propia.

Tabla 6

Resultados de la regresión exponencial

\begin{tabular}{lcccccc}
\hline & Coeficientes & $\begin{array}{c}\text { Error } \\
\text { típico }\end{array}$ & Estadístico t & Probabilidad & $\begin{array}{c}\text { Inferior } \\
95 \%\end{array}$ & $\begin{array}{c}\text { Superior } \\
95 \%\end{array}$ \\
\hline Intercepción & 12.86 & 0.43 & 29.28 & 0.000000002 & 11.84 & 13.87 \\
Variable & 0.28 & 0.07 & 3.97 & 0.00408446 & 0.11 & 0.44 \\
\hline
\end{tabular}

Fuente: Elaboración propia. 


\section{CONCLUSIONES}

Establecido lo anterior, es posible derivar conclusiones respecto al mercado de la leche y lácteos en México:

- La producción de leche y lácteos en México no satisface la demanda del mercado interno.

- México es dependiente del mercado externo, lo cual lo demuestra con puntos negativos en su balanza comercial, al importar más de lo que exporta.

- México es la novena zona económica con mayor consumo de leche y lácteos a nivel mundial.

- La cantidad de leche y lácteos consumida por cada mexicano es inferior a lo recomendado por la FAO. Se aconseja consumir dos vasos de leche al día; en promedio, un mexicano consume $1 \frac{1}{3}$ tasas de leche y lácteos diarias.

- Los patrones de consumo de leche y lácteos han permanecido similares año tras año, ya que el incremento del consumo de estos productos se relaciona con el crecimiento poblacional.

- El consumo de estos productos en las familias mexicanas ocupa el cuarto lugar del gasto familiar en todos los sectores económicos, un gasto similar entre el $7.91 \%$ y el $11.22 \%$.

- La leche y los lácteos son considerados bienes normales, ya que el gasto en leche y lácteos guarda una relación directa con el nivel de ingresos de cada decil. A un incremento en el ingreso, se refleja también un incremento en el consumo, a pesar que en el decil 9 (7.01 a 8.00 salarios mínimos) se refleje una pequeña disminución en el gasto en leche y lácteos.

\section{DISCUSIÓN}

Gracias al presente trabajo de investigación es posible comprender el panorama de la industria lechera en México de acuerdo al enfoque de estudio sobre su producción, comercialización y consumo, tal y como se planteó en el objetivo general. A pesar del crecimiento de la producción de leche y lácteos en México, aún no ha sido lo suficiente para cubrir la demanda interna. 


\section{PANORAMA SOBRE LA PRODUCCIÓN Y EL CONSUMO DE LECHE Y LÁCTEOS EN MÉXICO}

Tal y como lo explica Martínez y Villezca (2005), continúa presente la relación inversa entre el ingreso y el gasto en alimentos. Sin embargo, los patrones de consumo de alimentos se modificaron. En comparación, el sector más rico disminuyó su consumo de leche y lácteos, pasando de la segunda a la cuarta posición; el sector más pobre mantuvo en la cuarta posición a dicho consumo.

Al comparar los resultados con la redacción de Torres (1999), su consumo se ha presentado casi constante al. La leche y los productos sí reflejan un importante gasto en los hogares, no obstante, el rango de porcentaje consumido fue modificado; pasó de ser de un rango de 7\%$12 \%$ a un rango de 7.91\%-11.22\%. Esto es evidencia de la veracidad en lo citado por Hernández \& Hernández (2016), puesto que las tendencias a consumir productos que beneficien a la salud se han incrementado. Por consecuente, las familias con mayor poder adquisitivo tienen las ventajas al decidir en su consumo y seleccionar productos sustitutos de la leche, disminuyendo el gasto en productos de leche de vaca. En la siguiente tabla se comparan los resultados de investigación entre distintos autores:

Tabla 7

Comparación entre autores acerca del consumo de leche y lácteos en México

\begin{tabular}{lcccc}
\hline & Rodríguez & $\begin{array}{c}\text { Martínez y } \\
\text { Villezca }\end{array}$ & Torres & $\begin{array}{c}\text { Hernández y } \\
\text { Hernández }\end{array}$ \\
\hline $\begin{array}{l}\text { Tipo de relación entre ingreso y gasto en } \\
\text { leche. }\end{array}$ & Directa & Directa & Directa & - \\
$\begin{array}{l}\text { Posición del gasto en leche en el sector } \\
\text { más rico. }\end{array}$ & Cuarta & Segunda & - & - \\
$\begin{array}{l}\text { Posición del gasto en leche en el sector } \\
\text { más pobre. }\end{array}$ & Cuarta & Cuarta & - & - \\
$\begin{array}{l}\text { Porcentaje de gasto en leche en familias } \\
\text { ricas. }\end{array}$ & $11.22 \%$ & - & $12 \%$ & - \\
$\begin{array}{l}\text { Porcentaje de gasto en leche en familias } \\
\text { pobres. }\end{array}$ & $7.91 \%$ & - & $7 \%$ & - \\
$\begin{array}{l}\text { Sector que tiene puede decidir su } \\
\text { consumo. }\end{array}$ & Sector con & Sector con & Sector con & Sector con \\
& mayores & mayores & mayores & mayores \\
\hline
\end{tabular}

Fuente: Elaboración propia. 
PANORAMA SOBRE LA PRODUCCIÓN Y EL CONSUMO DE LECHE Y LÁCTEOS EN MÉXICO

Se exhorta a la población a informarse acerca de los beneficios tanto en la salud como económicos de todos los productos alimentarios para definir adecuadamente nuestros patrones de consumo. El gasto destinado por hogar para la alimentación continuará siendo distinto en cada familia, más que disminuir o eliminar ciertos productos de nuestra alimentación, proporcionaría amplios beneficios a la economía familiar.

\section{REFERENCIAS}

Aportela, V. R. (2010). Productos lácteos. En E. Mendoza Martínez, y M. d. Calvo Carrillo, Bromatología. Ciudad de México: Mc Graw Hill. pp. 123-128.

Cerón M. A. M. y Calvo C. M. C. (2010). Leche. En E. Mendoza Martínez, \& M. Calvo Carrillo, Bromatología. Ciudad de México: Mc Graw Hill. pp. 113-122.

Instituto Nacional de Estadística y Geografía INEGI. (2017). Encuesta Nacional de Ingreso y Gasto en Hogares ENIGH 2016. Recuperado de http://www.beta.inegi.org.mx/proyectos/enchogares/regulares/enigh/nc/2016/

Food and Agriculture Organization. (2018). Food Outlook. Milk and Milk Products Production. Recuperado de http://www.fao.org/3/ca0239en/CA0239EN.pdf

Hernández, G. y Hernández, A. (2016). Dairy and Products Semi-annual. Mexico's Dairy Products Increase in MY2016. Estados Unidos. Recuperado de: https://gain.fas.usda.gov/Recent\%20GAIN\%20Publications/Dairy\%20and\%20Prod ucts\%20Semi-annual_Mexico\%20City_Mexico_5-20-2016.pdf

How Milk Gets from the Cow to the Store. (2011). Retrieved from The Leading Source for Pros \& Cons of Controversial Issues. Recuperado de: https://milk.procon.org/view.resource.php?resourcelD=000658

Martínez, J. I. y Villezca, B. P. A. (2006). La alimentación en México. Ciencia UANL, 8(1), pp. 196-208. 
PANORAMA SOBRE LA PRODUCCIÓN Y EL CONSUMO DE LECHE Y LÁCTEOS EN MÉXICO

Schmid, R. (2009). The Untold Story of Milk. Washington: NewTrends Publishing Inc.

Torres T. F. (1999). Alimentación y economía en México: disyuntivas del tercer milenio. Revista de la Universidad de México, 576(577), pp. 50-55. Recuperado de:http://www.revistadelauniversidad.unam.mx/ojs_rum/files/journals/1/articles/148 63/public/14863-20261-1-PB.pdf 